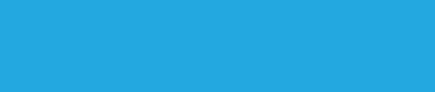

\title{
Phospho-ERK and sex steroids in the mPOA: involvement in male mouse sexual behaviour
}

\section{Arnaud Jean, Anne-Charlotte Trouillet, Njiva Andry Andrianarivelo, Sakina Mhaouty-Kodja and Hélène Hardin-Pouzet}

Sorbonne Universités, UPMC Univ Paris 06, INSERM, CNRS, Neuroscience Paris - Seine; Institut de Biologie Paris Seine, Paris, France
Correspondence should be addressed to $\mathrm{H}$ Hardin-Pouzet

Email

helene.pouzet@upmc.fr

\begin{abstract}
This paper aimed to investigate the mechanisms triggering ERK phosphorylation and its functional role in male sexual behaviour. ERK1/2-phosphorylated form was detected in the medial preoptic area of the hypothalamus (mPOA) during the sexual stimulation of naive and sexually experienced males who were killed $5 \mathrm{~min}$ after the first intromission. This mating-induced ERK phosphorylation was increased in sexually experienced males compared to that in naive mice. The functional role of the ERK1/2 pathway activation during sexual behaviour was explored with the administration of a MEK inhibitor, SL-327 (30 mg/kg, i.p.), $45 \mathrm{~min}$ before the contact with a receptive female. Inhibition of ERK phosphorylation was found to decrease sexual motivation in both naive and experienced males without altering their copulatory ability. The mechanisms potentially involved in this rapid ERK1/2 pathway activation were specified ex vivo on hypothalamic slices. A thirty-minute incubation with $100 \mathrm{nM}$ of testosterone $(\mathrm{T})$, dihydrotestosterone (DHT) or oestradiol (E2) led to ERK phosphorylation. No changes were observed after incubation with testosterone 3-(O-carboxymethyl)oxime-BSA (T-BSA), an impermeable to the plasma membrane form of testosterone. All these results indicate that ERK phosphorylation within the mPOA could be a key player in the motivational signalling pathway and considered as an index of sexual motivation. They also demonstrate the involvement of oestrogen receptor (ER) and androgen receptor (AR) transduction pathways in steroiddependent ERK activation.
\end{abstract}

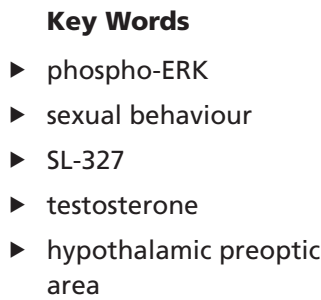

\section{Introduction}

Sexual behaviour in male rodents can be described as a series of behavioural elements cumulating in ejaculation. These involve approaches and olfactory investigations of the female during the motivational phase of sexual behaviour, which is followed by bouts of mounting, intromission and then ejaculation constituting the copulatory phase. The mating behaviour is governed by complex central interactions between different systems, which process sensory inputs, regulate rewards and integrate hormonal signals (Hull et al. 2002). The medial preoptic area of the hypothalamus (mPOA) represents the critical integrative site for male sexual behaviour regulation because lesions in this area are known to disrupt mounting, intromission and ejaculation in rats (De Jonge et al. 1989) and mounting behaviour in mice (Bean et al. 1981). Peripheral olfactory signals are received 
in sensory neurons of the olfactory epithelium and the vomeronasal organ, processed and relayed to the main and accessory olfactory bulbs and then to the medial amygdala and in bed nucleus of the stria terminalis before finally being integrated in the mPOA (Simerly \& Swanson 1986, Hull \& Dominguez 2007). In turn, activation of the mPOA network results in the stimulation of premotor areas responsible for the sexual response (Simerly \& Swanson 1988) and descending systems providing excitatory stimuli controlling the spinal generators for erection and ejaculation (Giuliano et al. 1996, Veening \& Coolen 2014).

The mPOA is activated in the first moments of mating as demonstrated by c-Fos mapping of the neural networks underlying the control of sexual behaviour (Baum \& Everitt 1992, Pfaus \& Heeb 1997). This has been confirmed by Taziaux and coworkers (Taziaux et al. 2011) by detecting the phosphorylated form of the mitogenactivated protein kinase/extracellular signal-regulated kinase (pERK), which was increased 10 min after exposure of sexually experienced males to female olfactory cues or after the display of coital behaviour. Hence, measuring pERK levels appeared as an accurate alternative tool to detect mPOA short-term activation as the timeline of kinase-mediated protein phosphorylation is much shorter than the induction of genomic transcription and translation of immediate early genes (IEG) (Murphy \& Blenis 2006). ERK phosphorylation is the final step of an intracellular signalling cascade that participates in the regulation of various cellular processes such as proliferation and differentiation (Shaul \& Seger 2007). Within the central nervous system, it plays a critical role in the modulation of synaptic plasticity, neuronal excitability, memory formation, storage and processing (Kelleher et al. 2004, Thomas \& Huganir 2004, Shiflett \& Balleine 2011a, Girault 2012), as well as in the control of reward, aversive or learning behaviour (Shiflett \& Balleine 2011b, Pascoli et al. 2014, Goto et al. 2015). Among the different signals triggering the ERK pathway activation, the stimulation of hormonal receptors, namely androgen (AR) and oestrogen receptors (ER), is known to be a potent activator of ERK phosphorylation in different brain areas such as the hippocampus (Zhao \& Brinton 2007, Pike et al. 2008) and the cerebellum (Wong et al. 2003) and also in other cell types in skeletal muscle (Estrada et al. 2003), the breast (Chia et al. 2011) and prostate (Liao et al. 2013).

Although pERK level has been shown to be increased in the mPOA of sexually experienced copulating males, currently no data are available on the hormonal signals triggering this phosphorylation and its functional relevance.

We first focused on the role of sex steroid hormones as the mPOA highly expresses AR (Raskin et al. 2009), which can be activated by testosterone (T) or its metabolite dihydrotestosterone (DHT). MPOA also expresses ER $\alpha$ (Swaney et al. 2012) and ER $\beta$ (Orikasa et al. 2002) activated by oestradiol (E2), which can be produced by neural aromatisation of $\mathrm{T}$. These experiments were conducted ex vivo on hypothalamic slices including the mPOA. This model has been found to efficiently decipher signalling pathways as it has the advantage of maintaining the integrity of the cellular microenvironment while using various pharmacological agents (Maolood et al. 2008, St-Louis et al. 2014). In the second part of our work, we analysed the functional role of ERK phosphorylation in vivo. We first established that ERK is phosphorylated at the beginning of the copulatory phase. We then compared the levels of ERK phosphorylation in naive and sexually experienced mice because ERK phosphorylation is involved in memory consolidation and network potentiation (Adams \& Sweatt 2002, Thomas \& Huganir 2004, Davis \& Laroche 2006). Indeed, although behavioural components of mating are known to be subjected to learning processes (Hull \& Dominguez 2006, Swaney et al. 2012), the potential role of ERK phosphorylation in this improvement has never been addressed. Finally, we administrated SL-327, an inhibitor of ERK phosphorylation crossing the bloodbrain barrier (Atkins et al. 1998, Valjent et al. 2000), to naive and experienced mice before the interaction with a receptive female to analyse the importance of ERK phosphorylation in conducting the various phases of sexual behaviour.

\section{Material and methods}

\section{Animals}

All the experiments were conducted in accordance with French and European laws (Decrees 2013-118, L214 and R214-87/130 and 2013/63/ECC) and are approved by the 'Charles Darwin' ethical committee (project number 01490-01).

C57Bl/6J mice (Janvier Breeding Centre, Le Genest, France) were bred in our animal facility and housed under a controlled photoperiod (12-h light and 12-h darkness cycle - lights on at $02: 00 \mathrm{~h}$ ) at $20 \pm 2^{\circ} \mathrm{C}$ with food and water ad libitum. Ten-week-old adult males were isolated for two weeks before any behavioural experiment. 


\section{Preparation of receptive females}

C57BL/6J females were ovariectomised under general anaesthesia (xylazine $10 \mathrm{mg} / \mathrm{kg}$ - ketamine $100 \mathrm{mg} /$ $\mathrm{kg}$, i.p.) and implanted with Silastic (Dow Corning) implants filled with $50 \mu \mathrm{g}$ of oestradiol-benzoate (SigmaAldrich) in $30 \mu \mathrm{L}$ of sesame oil. Four to five hours before the tests, they were subcutaneously treated with $1 \mathrm{mg}$ of progesterone (Sigma-Aldrich) in $100 \mu \mathrm{L}$ of sesame oil, as previously reported (Raskin et al. 2009). Female receptivity was verified before the beginning of experiments with a sexually experienced male.

\section{Male sexual experience}

Sexually experienced males were obtained after a 10-h mating session with a receptive female. The test was conducted under red-light illumination $2 \mathrm{~h}$ after lights off, videotaped and analysed to confirm that each male exhibited copulatory behaviour and reached the ejaculation. Male sexual behaviour was analysed by scoring the sniffing time before the first intromission, the latency to first intromission, the number of mounts and the mating duration defined as the time from the first intromission to ejaculation.

\section{Effect of sex steroid hormones on ERK phosphorylation within the mPOA}

Naive males were decapitated, brains were quickly removed and immersed in cooled artificial cerebrospinal fluid (aCSF): $117 \mathrm{mM} \mathrm{NaCl}, 4.7 \mathrm{mM} \mathrm{KCl}, 1.2 \mathrm{mM}$ $\mathrm{NaH}_{2} \mathrm{PO}_{4}, 25 \mathrm{mM} \mathrm{NaHCO}, 2.5 \mathrm{mM} \mathrm{CaCl}_{2}, 1.2 \mathrm{mM} \mathrm{MgCl}_{2}$ and $10 \mathrm{mM}$ glucose (Maolood et al. 2008, St-Louis et al. 2014). Coronal hypothalamic slices were cut with a Vibroslice (World Precision Instruments, Sarasota, USA). Using the anterior commissure as a landmark, one $400-\mu \mathrm{m}$-thick section including the mPOA was selected for each mouse, transferred to a brain slice chamber system and incubated in aCSF with either testosterone (T, $100 \mathrm{nM}$; Sigma-Aldrich), dihydrotestosterone (DHT, 100 nM; Sigma-Aldrich), oestradiol (E2, 100 nM; SigmaAldrich) or testosterone 3-(O-carboxymethyl)oximeBSA (T-BSA, 20-30 testosterone molecules per molecule BSA, $100 \mathrm{nM}$; Sigma-Aldrich) diluted in DMSO (7 males per group). Control slices were incubated with only DMSO. In a pilot experiment, the viability of the slices was verified by Fluoro-Jade staining (Millipore). After $30 \mathrm{~min}$ of treatment, mPOA was punched for Western blot analysis.
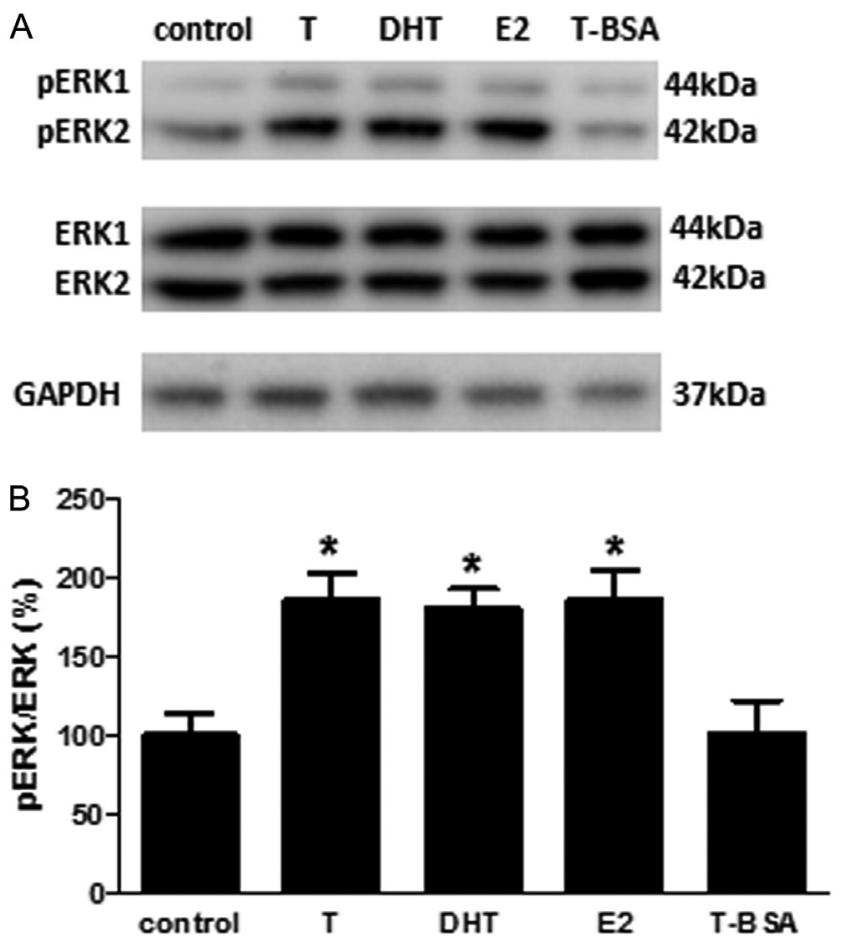

Figure 1

Activation of ERK by testosterone and its metabolites. Brain slices including $\mathrm{mPOA}$ were incubated $30 \mathrm{~min}$ in aCSF + DMSO (control), testosterone $(\mathrm{T}, 100 \mathrm{nM})$, dihydrotestosterone (DHT, $100 \mathrm{nM})$, oestradiol (E2, 100 nM) or testosterone 3-(O-carboxymethyl)oxime-BSA (T-BSA, $100 \mathrm{nM}$ ). (A) Representative blot detecting pERK, ERK and GAPDH in the mPOA after 30 min of incubation. (B) Densitometric evaluation of the Western blots. Results ( $p E R K / E R K$ ) are presented as mean percentage of the control group \pm S.E.M., $n=7$ in each group analysed by one-way ANOVA followed by Dunnett's multiple comparison test, ${ }^{*} P<0.05$ when compared to control group.

\section{Effect of sexual experience on mating-induced ERK phosphorylation}

Twenty-eight males were assigned to four different groups (7 males per group): naive staying in home cage (Naive: $\mathrm{N}$ ), naive allowed to mate with a receptive female (Naive + sex stimulus: $\mathrm{N}+\mathrm{S}$ ), sexually experienced (one mating 14 days before the experiment) staying in home cage (sexually experienced: E) and sexually experienced allowed to mate with a receptive female (sexually experienced + sex stimulus: $\mathrm{E}+\mathrm{S}$ ). Males were allowed to mate with a receptive female for $30 \mathrm{~min}$ and their sexual behaviour was analysed. Animals showing no sexual behaviour during the 30-min test were removed from the study. Five minutes after the first intromission, they were decapitated and the brain was rapidly removed. One 400- $\mu$ m-thick hypothalamic section was cut with a Vibroslice in cold $0.1 \mathrm{M}$ phosphate buffer (PB), and the mPOA was punched for Western blot analysis.

Published by Bioscientifica Ltd 

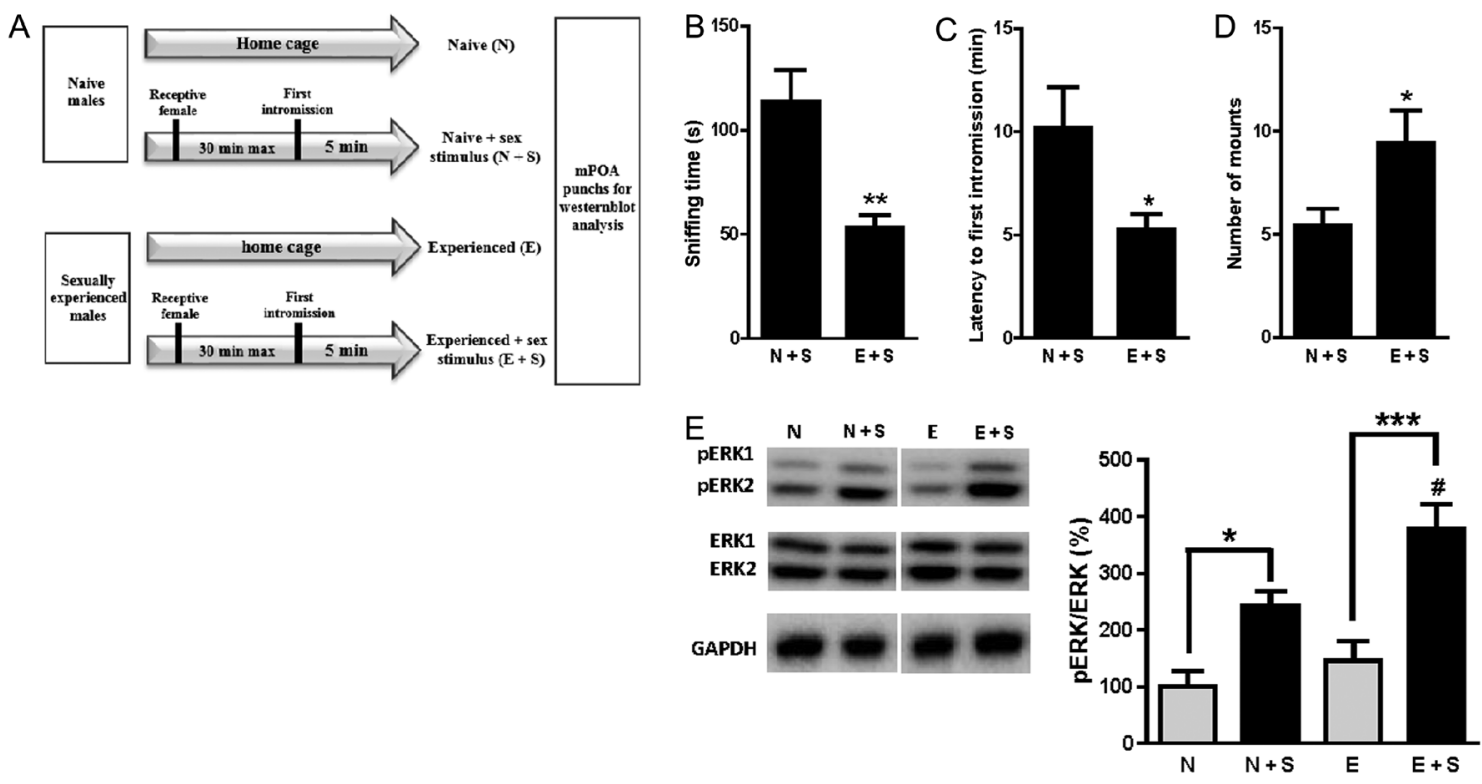

Figure 2

Mating-induced ERK phosphorylation in the MPOA and sexual experience. (A) Experimental design used to analyse the effect of mating and sexual experience on ERK phosphorylation in the mPOA. N: naive male staying in home cage, $\mathrm{N}+\mathrm{S}$ : naive male with sex stimulus killed 5 min after the first intromission, E: experienced male staying in home cage, E+S: experienced male with sex stimulus killed 5 min after the first intromission. Sexual behaviour expressed as (B) total anogenital sniffing time before the first intromission, (C) latency to the first intromission and (D) number of mounts for $\mathrm{N}+\mathrm{S}$ and $\mathrm{E}+\mathrm{S}$ males. Results are presented as mean \pm S.E.M. and analysed by Student's $t$ test, ${ }^{*} P<0.05, * * P<0.01$ compared to $\mathrm{N}+\mathrm{S}$ group. (E) Representative blot detecting pERK, ERK and GAPDH in the MPOA for N, N+S, E and E+S males and densitometric evaluation. Results (pERK/ERK) are presented as mean percentage of the $\mathrm{N}$ group \pm S.E.M. ( $n=7$ in each group) and analysed by two-way ANOVA followed by Bonferroni post hoc tests, ${ }^{*} P<0.05, * * * P<0,001,{ }^{*} P<0.05$ when compared to $\mathrm{N}+\mathrm{S}$ group.

\section{Involvement of ERK phosphorylation in the induction of sexual experience}

Forty-five minutes before mating, 17 naive males received an i.p. injection of SL-327 (Sigma-Aldrich, $30 \mathrm{mg} / \mathrm{kg}$ dissolved in 5\% DMSO, 5\% Tween 20 and 15\% polyethylene glycol 400), and 15 males received an i.p. injection of vehicle (Fig. 3A). Each male was tested in its home cage for $10 \mathrm{~h}$ after the introduction of a receptive female, and male sexual behaviour was analysed (mating 1). To determine the role of pERK in sexual experience, male sexual behaviour of the same animals was also analysed 14 days later without any injection (mating 2).
A

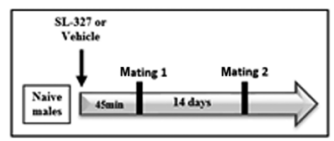

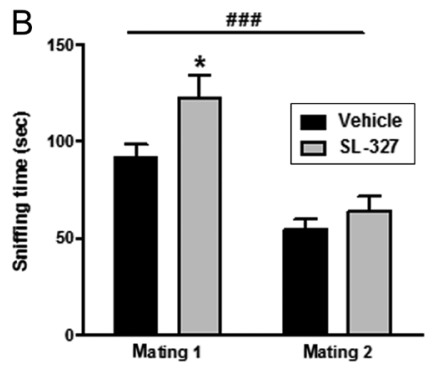
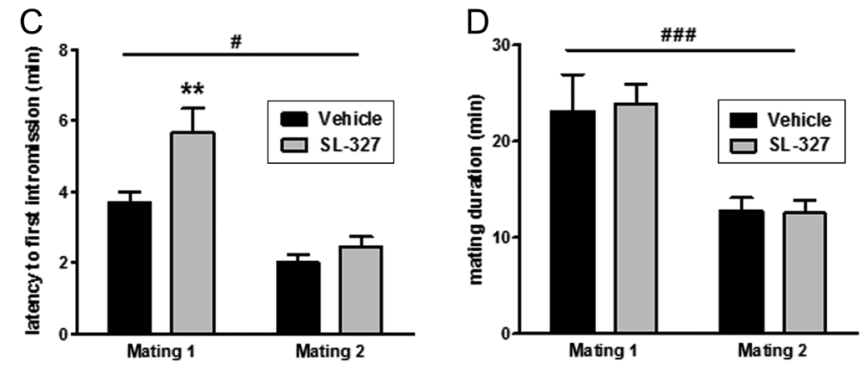

Figure 3

Involvement of ERK phosphorylation in the induction of male sexual experience. (A) Experimental design used to analyse the effect of a unique administration of the ERK phosphorylation inhibitor SL-327 administration ( $30 \mathrm{mg} / \mathrm{kg}$, i.p.) on sexual behaviour improvement. SL-327- and vehicleinjected groups were compared during the first and the second mating (separated by 14 days) for (B) total anogenital sniffing time before the first intromission, (C) latency to the first intromission and (D) mating duration. Results are presented as mean \pm S.E.M. ( $n=15$ for vehicle group and $n=17$ for SL-327 group) and analysed by two-way repeated measures ANOVA followed by Bonferroni post hoc tests. \#P<0.05, \#\# $P<0,001$ for sexual experience effect and $* P<0.05, * * P<0.01$ when compared to mating 1 of vehicle group.

http://joe.endocrinology-journals.org DOI: 10.1530/JOE-17-0025
๑) 2017 Society for Endocrinology Printed in Great Britain
Published by Bioscientifica Ltd 
A

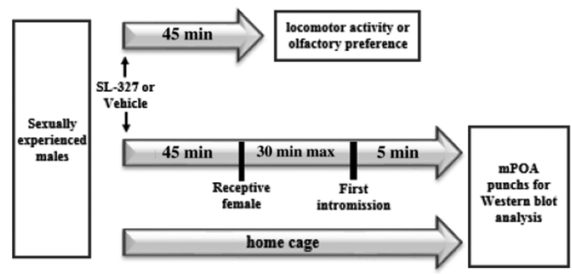

F

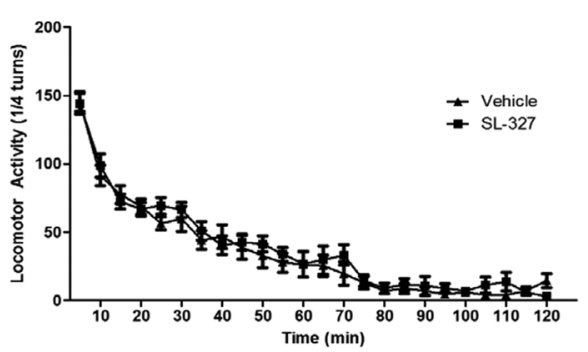

B

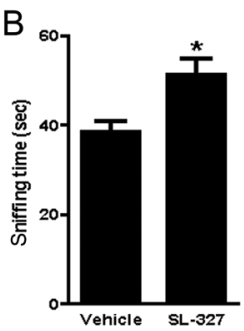

G

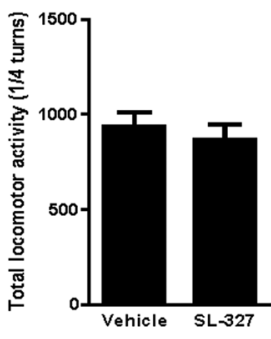

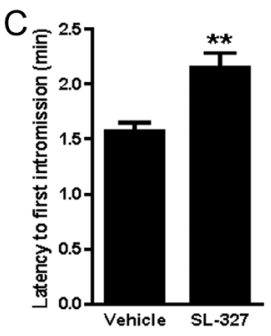

$\mathrm{H}$

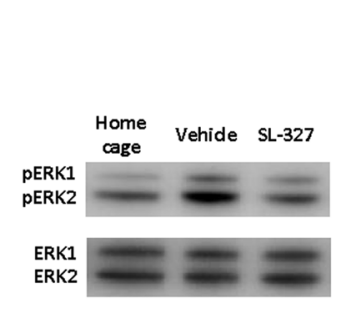

I
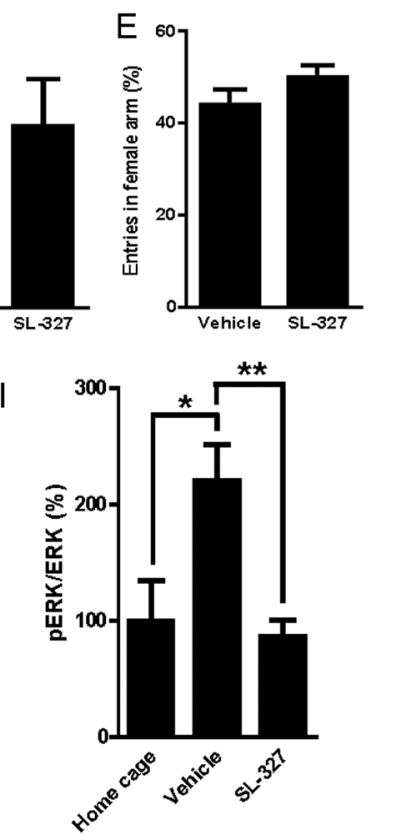

西

Figure 4

Involvement of ERK phosphorylation in sexual behaviour, locomotor activity and olfactory preference of sexually experienced males. (A) Experimental design used to analyse the effect of SL-327 administration $(30 \mathrm{mg} / \mathrm{kg}$, i.p.) on sexual behaviour, locomotor activity, olfactory preference and ERK phosphorylation in the mPOA of sexually experienced males. Sexual behaviour expressed as (B) total anogenital sniffing time before the first intromission and (C) latency to the first intromission ( $n=8$ in each group) presented as mean \pm S.E.M. and analysed by Student's $t$ test, $* P<0.05$ when compared to vehicle group. Olfactory preference in $D$ and $E$. (D) Olfactory preference score defined as the time spent sniffing the female - time spent sniffing the male/total time sniffing, (E) percentage of entries in female arm analysed by Student's $t$ test ( $n=11$ in each group). Locomotor activity in F and G. (F) Locomotor activity during the 120-min test, assessed by counting the number of beam interruptions every 5 -min intervals, analysed by two-way repeated-measures ANOVA followed by Bonferroni post hoc test, $(\mathrm{G})$ total locomotor activity, defined as the total number of beam interruptions during the 120-min test analysed by Student's test ( $n=11$ in each group). (H) Representative blot detecting pERK and ERK in the mPOA of experienced male mice kept in their home cage without a female (home cage) or injected either with SL-327 (SL-327) or vehicle (vehicle), put in the presence of a receptive female and killed $5 \mathrm{~min}$ after the first intromission. (I) Densitometric evaluation of the Western blot. Results (pERK/ERK) are expressed as mean percentage of the home cage group \pm s.E.M. and analysed by one-way ANOVA followed by Tukey post hoc test ( $n=8$ for vehicle and SL-327 groups, $n=5$ for home cage group). ${ }^{*} P<0.05, * * P<0.01$ compared to home cage group.

\section{Involvement of ERK phosphorylation in olfactory preference of sexually experienced males}

Twenty-two sexually experienced (one mating 14 days before the experiment) males were tested for olfactory preference (Fig. 4A). Two hours after lights were switched off, each male was placed into an enclosed Plexiglas Y-maze without any stimuli, for $5 \mathrm{~min}$ on two consecutive days, allowing them to adapt to the apparatus. On the third day, $45 \mathrm{~min}$ after i.p. injection of SL-327 (30 mg/ $\mathrm{kg}$ ) or vehicle, animals (11 per group) were given a choice between an anaesthetised receptive female or an anaesthetised gonadally intact male as previously described (Picot et al. 2014). The time spent sniffing at each partition and the number of entrances in the different arms were scored over the nine-minute test. Results were expressed as a preference score ((time spent sniffing the female - time spent sniffing the male)/total time sniffing) and in a percentage of the entries into the female arm. The maze was cleaned with $10 \%$ ethanol between trials.

\section{Involvement of ERK phosphorylation in locomotor activity of sexually experienced males}

Another group of 22 sexually experienced males were i.p. injected either with SL-327 $(30 \mathrm{mg} / \mathrm{kg})$ or vehicle (11 per group) $45 \mathrm{~min}$ before the test (Fig. $4 \mathrm{~A}$ ). Their locomotor activity was evaluated for $120 \mathrm{~min}$ using a circular corridor with four infrared beams placed at every $90^{\circ}$ (Imetronic, Pessac, France) in a low luminosity environment as previously described (Valjent et al. 2006). Locomotor activity during the 120-min test was assessed by counting the number of beam interruptions every 5-min intervals. The total locomotor activity represents the number of quarters travelled during the 120-min test. http://joe.endocrinology-journals.org DOI: $10.1530 / J O E-17-0025$
๑ 2017 Society for Endocrinology Printed in Great Britain 


\section{Involvement of ERK phosphorylation in the sexual behaviour of sexually experienced males}

A group of sixty sexually experienced males was either injected with SL-327 $(30 \mathrm{mg} / \mathrm{kg}$ ) or vehicle (8 per group) 45 min before a mating test (Fig. 4A). A control group of 5 sexually experienced males who stayed in their home cage were also analysed. Male sexual behaviour was followed, and five minutes after the first intromission, mPOA was punched for Western blot analysis.

\section{Western blot analysis}

Punches were homogenised in $50 \mathrm{mM}$ Tris ( $\mathrm{pH} 7.2$ ), $150 \mathrm{mM} \mathrm{NaCl}, 0.1 \%$ SDS, $0.5 \%$ sodium deoxycholate, $10 \mathrm{mM}$ EDTA, $10 \mathrm{mM}$ EGTA, 1\% Triton-X100 and 1\% protease inhibitor (Roche) and sonicated 7 times during $30 \mathrm{~s}$ (Bioruptor Plus; Diagenode, Seraing, Belgium). After centrifugation $\left(13 \mathrm{~min}, 15,495 \mathrm{~g}\right.$, at $\left.4^{\circ} \mathrm{C}\right)$, protein concentrations were determined in the supernatant with a Coomassie assay (Thermo Fisher Scientific). Samples were denatured in Laemmli buffer ( 5 min at $\left.95^{\circ} \mathrm{C}\right) .15 \mu \mathrm{g}$ protein were subjected to electrophoresis $(120 \mathrm{~V})$ on $4-12 \%$ Bis-Tris NuPAGE (Thermo Fisher Scientific) and electrotransferred overnight $(30 \mathrm{~V}$ at $4^{\circ} \mathrm{C}$ ) onto a PVDF membrane (Millipore). Blots were blocked with 5\% non-fat milk in Tris-buffered saline (TBS) and $0.2 \%$ Tween 20 (2h) and incubated overnight with primary antibodies against pERK1/2 (1:2000; polyclonal rabbit; Cell Signalling Technology), ERK1/2 (1:2000; polyclonal rabbit; Cell Signalling Technology) and GAPDH (glyceraldehyde 3-phosphate dehydrogenase; 1:20,000; monoclonal mouse; Santa Cruz Biotechnology) diluted in the same solution. Antibodies binding to blots were detected by $2-\mathrm{h}$ incubation with horseradish peroxidase anti-rabbit or anti-mouse secondary antibodies (1:10,000; Jackson ImmunoResearch). Signals were visualised with a picoSuper Signal detection kit (Thermo Fisher Scientific) with an Amersham Imager 600 (GE Healthcare Life Sciences) and quantified with ImageJ software (NIH). To determine the level of ERK activation, the phosphoERK signal was normalised to the total ERK signal and expressed as a percentage of the control.

\section{Statistical analysis}

Statistical analyses were performed using GraphPad Prism software (GraphPad Software). Data were expressed as mean \pm S.E.M. and compared with a Student's test.
One-way ANOVA followed by Dunnett's multiple comparison test was used to analyse slice treatments. Two-way ANOVA followed by Bonferroni tests were used to analyse the effects of mating and sexual experience on ERK phosphorylation. Two-way repeated-measures ANOVA followed by Bonferroni tests were used to analyse the effects of SL-327 treatment and the number of mating on sexual behaviour and also to analyse the effects of SL-327 treatment and time on locomotor activity. $P$ values of less than 0.05 were considered to be significant.

\section{Results}

\section{Activation of ERK by testosterone and its metabolites}

Slices containing mPOA were incubated with $\mathrm{T}$ or T-BSA, a non-aromatisable form of testosterone, which is impermeable to the plasma membrane (Nguyen et al. 2005). Incubations were also performed with testosterone metabolites such as DHT or E2. An incubation time of $30 \mathrm{~min}$ was chosen to be consistent with the rapid time course of ERK phosphorylation observed in vivo (Taziaux et al. 2011). Slices were incubated with $100 \mathrm{nM}$ of steroid corresponding to the plasmatic level of testosterone found in copulating mice (Coquelin \& Desjardins 1982, James \& Nyby 2002).

The level of ERK phosphorylation in the mPOA was analysed by Western blot (Fig. 1A). One-way ANOVA showed a significant effect of treatment on ERK phosphorylation ( $F=5.623, P<0.001$, Fig. 1B). Post hoc analyses showed an 86\% significant increase in ERK phosphorylation induced by $\mathrm{T}$ treatment when compared to the control group $(P<0.05)$. This increase was also significant for the incubation with DHT $(80 \%, P<0.05)$ or with E2 $(86 \%, P<0.05)$. By contrast, the levels of pERK were unchanged after incubation with T-BSA.

\section{Mating-induced ERK phosphorylation in the MPOA is increased by sexual experience}

Sexually naive $(\mathrm{N}+\mathrm{S}$ group) or experienced ( $\mathrm{E}+\mathrm{S}$ group) male mice were faced to a receptive female for $30 \mathrm{~min}$ and killed 5 min after the first intromission. Sexually naive ( $\mathrm{N}$ group) or experienced (S group) control mice were kept in their home cage without any contact with a receptive female (Fig. 2A). The 5-min delay was adapted to the time course of ERK phosphorylation, which is known to be activated in the first $10 \mathrm{~min}$ after female exposure (Taziaux et al. 2011).

Published by Bioscientifica Ltd 
Analyses of sexual parameters showed a 53\% reduction of the time spent in anogenital sniffing $(P<0.01)$, a $48 \%$ reduction of latency to the first intromission $(P<0.05)$ and a $74 \%$ increase in the number of mounts $(P<0.05)$ in the $\mathrm{E}+\mathrm{S}$ group compared to the $\mathrm{N}+\mathrm{S}$ group, confirming the improvement of sexual behaviour in experienced mice (Fig. 2B, C and D).

Two-way ANOVA demonstrated a significant effect of mating $\left(F_{(1-24)}=30.4, P<0.001\right)$ and sexual experience $\left(F_{(1-24)}=7.28, \quad P<0.05\right)$ but no interaction between these main effects $\left(F_{(1-24)}=1.78, \quad P>0.05\right)$ on ERK phosphorylation (Fig. 2E). Post hoc analyses showed that pERK level was increased for $\mathrm{N}+\mathrm{S}$ males killed 5 min after the first intromission $(\mathrm{N}+\mathrm{S}: 241 \pm 26.9, P<0.05)$, but was unchanged in the control experienced group (E: $146 \pm 33.9$ ) when both were compared to the control naive group (N: $100 \pm 27.9$ ). By contrast, ERK phosphorylation was increased in the $\mathrm{E}+\mathrm{S}$ group when compared to the $\mathrm{N}+\mathrm{S}$ group (E+S: $378 \pm 44, P<0.05)$. The changes in pERK levels were independent of any variation of total ERK protein normalised to the amount of GAPDH, demonstrating a specific regulation on ERK phosphorylation rather than on its protein level.

These results demonstrate thatERK was phosphorylated in the mPOA $5 \mathrm{~min}$ after the first intromission. The basal levels of pERK were not modified by sexual experience, but the ability of mPOA to phosphorylate ERK during mating was enhanced by sexual experience.

\section{Involvement of ERK phosphorylation in the regulation of male sexual behaviour}

To determine the role of ERK phosphorylation in the regulation of sexual behaviour, SL-327 $(30 \mathrm{mg} / \mathrm{kg}$, i.p.) was administered to naive males $45 \mathrm{~min}$ before the introduction of a receptive female (Fig. 3A) and its effect on sexual behaviour was analysed (mating 1). To determine whether the effects of this unique injection of SL-327 are transient or maintained in the long term, males were subjected to a second sexual behavioural test 14 days later (mating 2, Fig. 3B, C and D).

Two-way repeated measures ANOVA showed a significant effect of SL-327 treatment on the time spent in anogenital sniffing $\left(F_{(1-30)}=4.74, P<0.0001\right)$ and on the latency to first intromission $\left(F_{(1-30)}=51.68\right.$, $P<0.0001)$ but not on mating duration $\left(F_{(1-30)}=29.05\right.$, $P=0.92$ ). A significant effect of sexual experience was also observed on the time spent in anogenital sniffing $\left(F_{(1-30)}=39.87, P<0.0001\right)$, the latency to first intromission
$\left(F_{(1-30)}=5.78, P<0,05\right)$ and the mating duration $\left(F_{(1-30)}=\right.$ $29.05, P<0.0001)$. SL-327 treatment induced a significant increase by $34 \%(P<0.01)$ of the time spent in anogenital sniffing and a $53 \%$ increase $(P<0.05)$ of the latency to first intromission for SL-327 treated males compared to the vehicle group in the first mating test.

These behavioural differences were not observed during the second mating test for the sniffing time $(54.39 \pm 5.2$ vs $63.8 \pm 7.9)$, the latency to the first intromission $(2 \pm 0.21$ vs $2.46 \pm 0.26)$ and the mating duration $(12.7 \pm 1.38$ vs $12.5 \pm 1.31)$. This indicates that the SL-327 treatment transiently altered sexual behaviour but did not interfere with sexual improvement assessed two weeks later.

\section{Involvement of ERK phosphorylation in the control of male sexual behaviour in experienced males}

The short-term effect of the SL-327 (30 mg/kg, i.p.) treatment was further analysed on sexually experienced males by comparing the vehicle group and SL-327injected groups (Fig. 4A). The results showed a significant increase of $34 \%(P<0.05)$ in the time spent in anogenital sniffing and an increase of $37 \%(P<0.05)$ in the latency to the first intromission in the SL-327-treated group (Fig. 4B and C).

To ensure that SL-327 did not affect behaviours that might interfere with the expression of sexual behaviour controlled by the mPOA, olfactory preference towards female and locomotor activity were analysed $45 \mathrm{~min}$ after SL-327 or vehicle injection.

For olfactory preference, tested males were given a choice between an anaesthetised receptive female and an anaesthetised intact male. The total time spent in chemoinvestigation was similar between the groups $(221 \pm 6.8 \mathrm{~s}$ vs $242 \pm 11.2 \mathrm{~s})$. The percentage of entries in the female $\operatorname{arm}(44.1 \pm 3.3$ vs $50 \pm 2.7)$ and preference score $(14.1 \pm 2.9$ vs $16.1 \pm 4.2)$ were not modified by SL-327 administration (Fig. 4D and E).

Two-way repeated measures ANOVA demonstrated a significant effect of time $\left(F_{(23-460)}=84.02, P<0.0001\right)$ but not of treatment $\left(F_{(1-460)}=0.46, P=0.507\right)$ on locomotor activity measured at 5-min intervals (Fig. 4F). The cumulative activity expressed as the total number of quarters crossed during the 2-h test was not different between the two groups $(933 \pm 77.3$ vs $864 \pm 85.1$, Fig. 4G). Taken together, these data indicate that SL-327 does not interfere with olfactory preference and locomotor activity.

Published by Bioscientifica Ltd. 


\section{Phospho-ERK inhibition by SL-327}

The level of pERK was measured in the mPOA of experienced male mice kept in their home cage without a female (home cage) or injected either with SL-327 (SL-327) or vehicle (vehicle), put in the presence of a receptive female and killed $5 \mathrm{~min}$ after the first intromission (Fig. 4A). Oneway ANOVA showed the treatment had a significant effect on the ERK phosphorylation level $(F=8.020, P<0.005)$. Mated mice injected with the vehicle had significantly higher levels of pERK level than unmated males $(220 \pm 31$ vs $100 \pm 34, P<0.05)$. This increase was totally abolished by SL-327 treatment $(86.4 \pm 14$, Fig. $4 \mathrm{H}$ and I).

Taken together, these results demonstrate that blocking ERK phosphorylation increased the time spent in chemoinvestigation and delayed the initiation of sexual behaviour in both naive and experienced mice. These transient effects did not disrupt the sexual improvement of mating and were not due to altered olfactory preference or locomotor activity.

\section{Discussion}

The medial preoptic area of the hypothalamus (mPOA) is considered as the main integrative site for male sexual behaviour regulation (Hull \& Dominguez 2006), established for a long time by lesion and stimulation experiments. Studies in a variety of rodents demonstrated an increased expression of immediate early gene (IEG), such as c-Fos, in the mPOA with sexual activity (Robertson et al. 1991, Heeb \& Yahr 1996, Kollack-Walker \& Newman 1997, Nutsch et al. 2016). As pERK was induced in the first $10 \mathrm{~min}$ of sexually experienced male coital behaviour by Taziaux and coworkers (Taziaux et al. 2011), this signalling pathway was suspected to be one of the first events involved in the control of sexual behaviour. This paper investigated the mechanisms triggering ERK phosphorylation and its functional role in male sexual behaviour.

We first confirmed the rapid activation of ERK phosphorylation in the early phases of copulation. pERK was increased $5 \mathrm{~min}$ after the first intromission in both naive and experienced males. Given the ability of steroid hormones to induce its phosphorylation (Wong et al. 2003, Abrahám et al. 2004, Pike et al. 2008, Liao et al. 2013) and the increased circulating levels of testosterone ( $\mathrm{T}$ ) during an interaction with a female (Batty 1978, Coquelin \& Desjardins 1982), we thus investigated whether $\mathrm{T}$ or its metabolites were able to induce ERK phosphorylation within the mPOA. Thirtyminute treatment of hypothalamic slices by $\mathrm{T}$ was found to induce ERK activation. By contrast, treatment with the plasma membrane-impermeable T-BSA was inefficient, thereby eliminating a potential membranedependent signalling pathway. Furthermore, DHT treatment reproduced $\mathrm{T}$ activation of ERK, suggesting the involvement of an intracellular AR-dependent mechanism in agreement with previously described regulation of ERK phosphorylation by the intracellular AR in hippocampal neurons (Nguyen et al. 2005). T-induced effects were also mimicked by E2 treatment, evidencing the participation of ER in steroid-mediated ERK phosphorylation. The possibility that steroids might use either the AR or the ER pathway to mediate the same effect has already been described in the male rat namely to restore a complete sexual behaviour after castration (Attila et al. 2010). Finally, the rapid ERK activation (30 min) suggests a rapid non-genomic action of sex steroids in the mPOA. In this way, it is now well established that cytoplasmic ER or AR can rapidly activate members of the ERK signalling cascade, via direct interaction with the non-tyrosine kinase receptor Src (Migliaccio et al. 2000). Of interest, sex steroids can also activate members of the ERK pathway in hippocampal and cerebellar neurons in less than $15 \mathrm{~min}$ (Wong et al. 2003, Nguyen et al. 2005).

Because the ERK pathway is involved in behavioural learning and reinforcing processes (Adams \& Sweatt 2002, Thomas \& Huganir 2004), the level of ERK phosphorylation was compared between naive and experienced males. Sexually experienced males showed a typical improved behaviour with decreased anogenital sniffing time and latency to the first intromission and also a higher number of mounts (Hull \& Dominguez 2006, Swaney et al. 2012), thus demonstrating an enhancement of sexual motivation (Fiorino \& Phillips 1999).

ERK phosphorylation was found to be increased within the mPOA 5 min after the first intromission in both naive and experienced males. To our knowledge, no study has reported an increase of ERK phosphorylation in less than $5 \mathrm{~min}$ of stimulation. Thus, it can be hypothesised that ERK phosphorylation was triggered by events taking place at least $5 \mathrm{~min}$ before the killing, thus during the motivational phase of sexual behaviour. In this line of thought, the level of ERK phosphorylation may thus represent an index of sexual motivation and performance.

Interestingly, mating-induced ERK phosphorylation was more elevated in sexually experienced males who are supposed to be more sensitive to androgen as they display http://joe.endocrinology-journals.org DOI: $10.1530 / J O E-17-0025$
๑) 2017 Society for Endocrinology Printed in Great Britain
Published by Bioscientifica Ltd 
elevated levels of circulating testosterone and higher AR levels in the mPOA (Swaney et al. 2012). They also show an increased number of copulation-induced c-Fospositive neurons in their mPOA (Lumley \& Hull 1999). As we found that $\mathrm{T}$ and its metabolites could induce a rapid activation of the MAPK pathway, the increased ability of experienced males to phosphorylate ERK could thus be explained by a higher sensitivity of the mPOA to steroids.

To assess the functional role of ERK phosphorylation in sexual behaviour, males were treated with SL-327, a brain-penetrating selective inhibitor of MAP kinase/ERK kinase (MEK1/2), the enzyme which selectively activates ERK (Selcher et al. 1999). Naive males treated with SL-327 showed decreased sexual motivation without altering the copulatory phase as mating duration and copulatory patterns remained similar to the vehicle group. These results are consistent with those obtained by Niessen and coworkers (Niessen et al. 2013) in which c-Fos inhibition in the mPOA resulted in the reduction of appetitive male sexual behaviour in the quail. In experienced males treated with SL-327, similar results were observed: anogenital sniffing time and latency to the first intromission were increased compared to experienced males treated with the vehicle. The increase observed in the motivational phase length could be considered specific and not linked to a side effect of the SL-327 treatment as locomotion was not altered. The rapid non-genomic ERK activation mediated by steroids that we exhibited ex vivo could be one of the mechanisms involved in mating-induced ERK activation as sexual motivation was shown to be partly regulated by rapid non-classical actions of steroids in the quail (Seredynski et al. 2013).

Pre-treatment of naive males with SL-327 before their first sexual behaviour did not alter the improvement of their sexual performance observed during the second mating test. Thus, inhibition of ERK phosphorylation did not disrupt the learning associated with sexual experience even if the motivational phase was prolonged. These results show that ERK phosphorylation is not required for learning processes of sexual experience as it has been previously demonstrated in other brain areas for spatial memory (Blum et al. 1999) and fear conditioning (Schafe et al. 2008).

To summarise, our results show that ERK phosphorylation probably took place during the motivational phase, that experienced males, who are more motivated than naive males, have an increased level of phosphorylation and that inhibition of ERK phosphorylation decreased sexual motivation. These results strongly suggest that ERK phosphorylation in the mPOA could be considered as a key player in the motivational signalling pathway transduction and as an index of sexual motivation.

Our results also revealed new aspects regarding the mechanisms leading to olfactory preference as it was not modified by SL-327 treatment although exposure of a male to an oestrous female was found to activate the ERK pathway in the main and accessory olfactory bulb and in the amygdala (Taziaux et al. 2011). These data may be linked to the observation that pheromone stimulation of a male mouse causes ERK activation in the vomeronasal organ, in amygdala and in the hypothalamus but not in the accessory olfactory bulb (Dudley et al. 2001). Furthermore, even if olfactory interactions are important for the copulatory behaviour (Keller et al. 2006), several other neuronal pathways coming from BST, septum and other areas converging on the mPOA (Dhungel et al. 2011) are activated when a male is placed in front of a receptive female (Pfaus \& Heeb 1997). These results are also consistent with data reported by Satoh and coworkers (Satoh et al. 2011) showing that mice lacking ERK2 in the brain have deficits in social interaction without olfactory defect. Taken together, these observations indicate that ERK phosphorylation is not essential to induce olfactory preference. Furthermore, it suggests that the mechanisms controlling the motivational phase and the MPOA activation are integrated downstream the olfactory bulb.

In conclusion, this paper has established for the first time that ERK is phosphorylated within the MPOA during the early events of the male copulation in both naive and sexually experienced males. This phosphorylation can be triggered ex vivo by rapid action of testosterone or its metabolites such as DHT or E2. Although the ERK pathway was involved in numerous learning processes, ERK phosphorylation in the MPOA is not an underlying factor in sexual improvement induced by sexual experience. Nevertheless, the level of pERK could be considered as an index of sexual motivation as sexually experienced males exhibited an increase in mating-induced ERK activation, and its inhibition decreased the motivational phase efficiency.

Our results could represent an interesting tool for the investigation of the effects of hormonomimetic molecules able to interfere with the control of sexual behaviour, such as endocrine disruptors. Furthermore, the ability to rapidly activate the ERK pathway on an ex vivo model 
of mPOA slices could also be a very useful tool to help decipher the negative effects of such molecules perturbing the signalling pathways of steroid hormones.

\section{Declaration of interest}

The authors declare that there is no conflict of interest that could be perceived as prejudicing the impartiality of the research reported.

\section{Funding}

This work was supported by UPMC, CNRS and INSERM.

\section{Acknowledgements}

The authors thank Dr J Caboche and Dr P Vanhoutte for sharing their expertise on ERK and their valuable discussion about the manuscript.

\section{References}

Abrahám IM, Todman MG, Korach KS \& Herbison AE 2004 Critical in vivo roles for classical estrogen receptors in rapid estrogen actions on intracellular signaling in mouse brain. Endocrinology 145 3055-3061. (doi:10.1210/en.2003-1676)

Adams JP \& Sweatt JD 2002 Molecular psychology: roles for the ERK MAP kinase cascade in memory. Annual Review of Pharmacology and Toxicology 42 135-163. (doi:10.1146/annurev. pharmtox.42.082701.145401)

Atkins CM, Selcher JC, Petraitis JJ, Trzaskos JM \& Sweatt JD 1998 The MAPK cascade is required for mammalian associative learning. Nature Neuroscience 1 602-609. (doi:10.1038/2836)

Attila M, Oksala R \& Agmo A 2010 Sexual incentive motivation in male rats requires both androgens and estrogens. Hormones and Behavior $\mathbf{5 8}$ 341-351. (doi:10.1016/j.yhbeh.2009.08.011)

Batty J 1978 Acute changes in plasma testosterone levels and their relation to measures of sexual behaviour in the male house mouse (Mus musculus). Animal Behaviour 26 349-357. (doi:10.1016/00033472(78)90053-2)

Baum MJ \& Everitt BJ 1992 Increased expression of c-fos in the medial preoptic area after mating in male rats: role of afferent inputs from the medial amygdala and midbrain central tegmental field. Neuroscience 50 627-646. (doi:10.1016/0306-4522(92)90452-8)

Bean NY, Nunez AA \& Conner R 1981 Effects of medial preoptic lesions on male mouse ultrasonic vocalizations and copulatory behavior. Brain Research Bulletin 6 109-112. (doi:10.1016/S03619230(81)80033-0)

Blum S, Moore AN, Adams F \& Dash PK 1999 A mitogen-activated protein kinase cascade in the CA1/CA2 subfield of the dorsal hippocampus is essential for long-term spatial memory. Journal of Neuroscience 19 3535-3544.

Chia KM, Liu J, Francis GD \& Naderi A 2011 A feedback loop between androgen receptor and ERK signaling in estrogen receptor-negative breast cancer. Neoplasia 13 154-166. (doi:10.1593/neo.101324)

Coquelin A \& Desjardins C 1982 Luteinizing hormone and testosterone secretion in young and old male mice. American Journal of Physiology 243 E257-E263.

Davis S \& Laroche S 2006 Mitogen-activated protein kinase/extracellular regulated kinase signalling and memory stabilization: a review. Genes, Brain and Behavior 5 61-72. (doi:10.1111/j.1601-183X.2006.00230.x)

De Jonge FH, Louwerse AL, Ooms MP, Evers P, Endert E \& van de Poll NE 1989 Lesions of the SDN-POA inhibit sexual behavior of male
Wistar rats. Brain Research Bulletin 23 483-492. (doi:10.1016/03619230(89)90194-9)

Dhungel S, Urakawa S, Kondo Y \& Sakuma Y 2011 Olfactory preference in the male rat depends on multiple chemosensory inputs converging on the preoptic area. Hormones and Behavior 59 193-199. (doi:10.1016/j.yhbeh.2010.11.011)

Dudley CA, Chakravarty S \& Barnea A 2001 Female odors lead to rapid activation of mitogen-activated protein kinase (MAPK) in neurons of the vomeronasal system. Brain Research 915 32-46. (doi:10.1016/ S0006-8993(01)02820-7)

Estrada M, Espinosa A, Müller M \& Jaimovich E 2003 Testosterone stimulates intracellular calcium release and mitogen-activated protein kinases via a $G$ protein-coupled receptor in skeletal muscle cells. Endocrinology 144 3586-3597. (doi:10.1210/en.2002-0164)

Fiorino DF \& Phillips AG 1999 Facilitation of sexual behavior and enhanced dopamine efflux in the nucleus accumbens of male rats after D-amphetamine-induced behavioral sensitization. Journal of Neuroscience 19 456-463.

Girault J-A 2012 Signaling in striatal neurons: the phosphoproteins of reward, addiction, and dyskinesia. Progress in Molecular Biology and Translational Science 106 33-62. (doi:10.1016/B978-0-12-3964564.00006-7)

Giuliano F, Rampin O, Brown K, Courtois F, Benoit G \& Jardin A 1996 Stimulation of the medial preoptic area of the hypothalamus in the rat elicits increases in intracavernous pressure. Neuroscience Letters 209 1-4. (doi:10.1016/0304-3940(96)12594-5)

Goto A, Nakahara I, Yamaguchi T, Kamioka Y, Sumiyama K, Matsuda M, Nakanishi S \& Funabiki K 2015 Circuit-dependent striatal PKA and ERK signaling underlies rapid behavioral shift in mating reaction of male mice. PNAS 112 6718-6723. (doi:10.1073/pnas.1507121112)

Heeb MM \& Yahr P 1996 c-Fos immunoreactivity in the sexually dimorphic area of the hypothalamus and related brain regions of male gerbils after exposure to sex-related stimuli or performance of specific sexual behaviors. Neuroscience 72 1049-1071. (doi:10.1016/0306-4522(95)00602-8)

Hull EM \& Dominguez JM 2006 Getting his act together: roles of glutamate, nitric oxide, and dopamine in the medial preoptic area. Brain Research 1126 66-75. (doi:10.1016/j.brainres.2006.08.031)

Hull EM \& Dominguez JM 2007 Sexual behavior in male rodents. Hormones and Behavior 52 45-55. (doi:10.1016/j.yhbeh.2007.03.030)

Hull EM, Meisel RL \& Sachs BD 20021 - Male sexual behavior A2 - Pfaff, Donald W. In Hormones, Brain and Behavior, pp 3-137. Eds AP Arnold, SE Fahrbach, AM Etgen \& RT Rubin. San Diego, CA, USA: Academic Press.

James PJ \& Nyby JG 2002 Testosterone rapidly affects the expression of copulatory behavior in house mice (Mus musculus). Physiology and Behavior 75 287-294. (doi:10.1016/S0031-9384(01)00666-7)

Kelleher RJ, Govindarajan A, Jung H-Y, Kang H \& Tonegawa S 2004 Translational control by MAPK signaling in long-term synaptic plasticity and memory. Cell 116 467-479. (doi:10.1016/S00928674(04)00115-1)

Keller M, Douhard Q, Baum MJ \& Bakker J 2006 Sexual experience does not compensate for the disruptive effects of zinc sulfate-lesioning of the main olfactory epithelium on sexual behavior in male mice. Chemical Senses 31 753-762. (doi:10.1093/chemse/bj1018)

Kollack-Walker S \& Newman SW 1997 Mating-induced expression of c-fos in the male Syrian hamster brain: role of experience, pheromones, and ejaculations. Journal of Neurobiology 32 481-501. (doi:10.1002/ (SICI) 1097-4695(199705)32:5<481::AID-NEU4>3.0.CO;2-1)

Liao RS, Ma S, Miao L, Li R, Yin Y \& Raj GV 2013 Androgen receptormediated non-genomic regulation of prostate cancer cell proliferation. Translational Andrology and Urology 2 187-196. (doi:10.3978/j.issn.2223-4683.2013.09.07)

Lumley LA \& Hull EM 1999 Effects of a D1 antagonist and of sexual experience on copulation-induced Fos-like immunoreactivity in the http://joe.endocrinology-journals.org

DOI: $10.1530 / \mathrm{JOE}-17-0025$
๑ 2017 Society for Endocrinology Printed in Great Britain
Published by Bioscientifica Ltd 
medial preoptic nucleus. Brain Research 829 55-68. (doi:10.1016/ S0006-8993(99)01338-4)

Maolood N, Hardin-Pouzet H \& Grange-Messent V 2008 Matrix metalloproteinases MMP2 and MMP9 are upregulated by noradrenaline in the mouse neuroendocrine hypothalamus. European Journal of Neuroscience 27 1143-1152. (doi:10.1111/j.14609568.2008.06099.x)

Migliaccio A, Castoria G, Di Domenico M, de Falco A, Bilancio A, Lombardi M, Barone MV, Ametrano D, Zannini MS, Abbondanza C, et al. 2000 Steroid-induced androgen receptor-oestradiol receptor beta-Src complex triggers prostate cancer cell proliferation. EMBO Journal 19 5406-5417. (doi:10.1093/emboj/19.20.5406)

Murphy LO \& Blenis J 2006 MAPK signal specificity: the right place at the right time. Trends in Biochemical Sciences 31 268-275. (doi:10.1016/j. tibs.2006.03.009)

Nguyen T-VV, Yao M \& Pike CJ 2005 Androgens activate mitogenactivated protein kinase signaling: role in neuroprotection. Journal of Neurochemistry 94 1639-1651. (doi:10.1111/j.1471-4159.2005.03318.x)

Niessen N-A, Balthazart J, Ball GF \& Charlier TD 2013 c-fos downregulation inhibits testosterone-dependent male sexual behavior and the associated learning. European Journal of Neuroscience $\mathbf{3 8}$ 3325-3337. (doi:10.1111/ejn.12321)

Nutsch VL, Will RG, Robison CL, Martz JR, Tobiansky DJ \& Dominguez JM 2016 Colocalization of mating-induced Fos and D2-like dopamine receptors in the medial preoptic area: influence of sexual experience. Frontiers in Behavioral Neuroscience 10 75. (doi:10.3389/ fnbeh.2016.00075)

Orikasa C, Kondo Y, Hayashi S, McEwen BS \& Sakuma Y 2002 Sexually dimorphic expression of estrogen receptor $\beta$ in the anteroventral periventricular nucleus of the rat preoptic area: implication in luteinizing hormone surge. PNAS 99 3306-3311. (doi:10.1073/ pnas.052707299)

Pascoli V, Cahill E, Bellivier F, Caboche J \& Vanhoutte P 2014 Extracellular signal-regulated protein kinases 1 and 2 activation by addictive drugs: a signal toward pathological adaptation. Biological Psychiatry 76 917-926. (doi:10.1016/j.biopsych.2014.04.005)

Pfaus JG \& Heeb MM 1997 Implications of immediate-early gene induction in the brain following sexual stimulation of female and male rodents. Brain Research Bulletin 44 397-407. (doi:10.1016/S03619230(97)00219-0)

Picot M, Naulé L, Marie-Luce C, Martini M, Raskin K, Grange-Messent V, Franceschini I, Keller M \& Mhaouty-Kodja S 2014 Vulnerability of the neural circuitry underlying sexual behavior to chronic adult exposure to oral bisphenol A in male mice. Endocrinology 155 502-512. (doi:10.1210/en.2013-1639)

Pike CJ, Nguyen T-VV, Ramsden M, Yao M, Murphy MP \& Rosario ER 2008 Androgen cell signaling pathways involved in neuroprotective actions. Hormones and Behavior 53 693-705. (doi:10.1016/j.yhbeh.2007.11.006)

Raskin K, de Gendt K, Duittoz A, Liere P, Verhoeven G, Tronche F \& Mhaouty-Kodja S 2009 Conditional inactivation of androgen receptor gene in the nervous system: effects on male behavioral and neuroendocrine responses. Journal of Neuroscience 29 4461-4470. (doi:10.1523/JNEUROSCI.0296-09.2009)

Robertson GS, Pfaus JG, Atkinson LJ, Matsumura H, Phillips AG \& Fibiger HC 1991 Sexual behavior increases c-fos expression in the forebrain of the male rat. Brain Research 564 352-357. (doi:10.1016/00068993(91)91477-I)

Satoh Y, Endo S, Nakata T, Kobayashi Y, Yamada K, Ikeda T, Takeuchi A, Hiramoto T, Watanabe Y \& Kazama T 2011 ERK2 contributes to the control of social behaviors in mice. Journal of Neuroscience $\mathbf{3 1}$ 11953-11967. (doi:10.1523/JNEUROSCI.2349-11.2011)
Schafe GE, Swank MW, Rodrigues SM, Debiec J \& Doyère V 2008 Phosphorylation of ERK/MAP kinase is required for long-term potentiation in anatomically restricted regions of the lateral amygdala in vivo. Learning and Memory 15 55-62. (doi:10.1101/lm.746808)

Selcher JC, Atkins CM, Trzaskos JM, Paylor R \& Sweatt JD 1999 A necessity for MAP kinase activation in mammalian spatial learning. Learning and Memory 6 478-490. (doi:10.1101/1m.6.5.478)

Seredynski AL, Balthazart J, Christophe VJ, Ball GF \& Cornil CA 2013 Neuroestrogens rapidly regulate sexual motivation but not performance. Journal of Neuroscience 33 164-174. (doi:10.1523/ JNEUROSCI.2557-12.2013)

Shaul YD \& Seger R 2007 The MEK/ERK cascade: from signaling specificity to diverse functions. Biochimica et Biophysica Acta (BBA): Molecular Cell Research 1773 1213-1226. (doi:10.1016/j.bbamcr.2006.10.005)

Shiflett MW \& Balleine BW 2011a Molecular substrates of action control in cortico-striatal circuits. Progress in Neurobiology 95 1-13. (doi:10.1016/j.pneurobio.2011.05.007)

Shiflett MW \& Balleine BW 2011b Contributions of ERK signaling in the striatum to instrumental learning and performance. Behavioural Brain Research 218 240-247. (doi:10.1016/j.bbr.2010.12.010)

Simerly RB \& Swanson LW 1986 The organization of neural inputs to the medial preoptic nucleus of the rat. Journal of Comparative Neurology 246 312-342. (doi:10.1002/cne.902460304)

Simerly RB \& Swanson LW 1988 Projections of the medial preoptic nucleus: a phaseolus vulgaris leucoagglutinin anterograde tracttracing study in the rat. Journal of Comparative Neurology 270 209-242. (doi:10.1002/cne.902700205)

St-Louis R, Parmentier C, Grange-Messent V, Mhaouty-Kodja S \& HardinPouzet H 2014 Reactive oxygen species are physiological mediators of the noradrenergic signaling pathway in the mouse supraoptic nucleus. Free Radical Biology and Medicine 71 231-239. (doi:10.1016/j. freeradbiomed.2014.03.024)

Swaney WT, Dubose BN, Curley JP \& Champagne FA 2012 Sexual experience affects reproductive behavior and preoptic androgen receptors in male mice. Hormones and Behavior $61472-478$. (doi:10.1016/j.yhbeh.2012.01.001)

Taziaux M, Keller M, Balthazart J \& Bakker J 2011 Rapid activation of phosphorylated mitogen-activated protein kinase after sexual stimulation in male mice: NeuroReport 22 294-298. (doi:10.1097/ WNR.0b013e3283460f35)

Thomas GM \& Huganir RL 2004 MAPK cascade signalling and synaptic plasticity. Nature Reviews: Neuroscience 5 173-183. (doi:10.1038/nrn1346)

Valjent E, Corvol JC, Pages C, Besson MJ, Maldonado R \& Caboche $\mathrm{J} 2000$ Involvement of the extracellular signal-regulated kinase cascade for cocaine-rewarding properties. Journal of Neuroscience $\mathbf{2 0}$ 8701-8709.

Valjent E, Corvol J-C, Trzaskos JM, Girault J-A \& Hervé D 2006 Role of the ERK pathway in psychostimulant-induced locomotor sensitization. BMC Neuroscience 7 20. (doi:10.1186/1471-2202-7-20)

Veening JG \& Coolen LM 2014 Neural mechanisms of sexual behavior in the male rat: emphasis on ejaculation-related circuits. Pharmacology, Biochemistry, and Behavior 121 170-183. (doi:10.1016/j.pbb.2013.12.017)

Wong JK, Le HH, Zsarnovszky A \& Belcher SM 2003 Estrogens and ICI182,780 (Faslodex) modulate mitosis and cell death in immature cerebellar neurons via rapid activation of p44/p42 mitogen-activated protein kinase. Journal of Neuroscience 23 4984-4995.

Zhao L \& Brinton RD 2007 Estrogen receptor alpha and beta differentially regulate intracellular $\mathrm{Ca}(2+)$ dynamics leading to ERK phosphorylation and estrogen neuroprotection in hippocampal neurons. Brain Research 1172 48-59. (doi:10.1016/j. brainres.2007.06.092)

Received in final form 27 March 2017

Accepted 29 March 2017

Accepted Preprint published online 29 March 2017 http://joe.endocrinology-journals.org

DOI: 10.1530/JOE-17-0025
(C) 2017 Society for Endocrinology Printed in Great Britain
Published by Bioscientifica Ltd. 